systematic manner though generally grouped by aetiology. Some illustrate other associations with joint pain (e.g. disuse atrophy, sarcoma, fluorosis). In three or four cases, British radiologists might offer alternative diagnoses and in one or two others the salient features are difficult to see.

The atlas is preceded by text including an international classification of joint disease in English, Latin and German and short descriptions of the individual conditions. Technical German does not translate easily into English and some of the terminology is not in current English usage, though understandable.

It is difficult to be sure for whom this Atlas is intended. Radiologists and rheumatologists in training would profit from it if they have already good basic background knowledge of the subject, and those already in practice will find it of interest, but it is very much a book to be available in a library for additional study.

\section{Handbook of Ophthalmologic Emergencies}

By George M. Coombes. Pp. 251, illustrated. Henry Kimpton: London. 1973. £3.60.

In the foreword to this very useful handbook on emergency procedures in ophthalmology, one of the many qualities cited in support of the editor is the experience he gained in the 1967 Israeli war. Without detracting from his valour and enterprise, one must only regard this as a 6-day crash course; of course he has others, including now this helpful book. Ophthalmic emergencies are both grave and frightening, so the casualty officer dealing with them needs a manual such as this to guide him through the immediate examination, investigation and treatment until the patient comes under the care of an ophthalmologist. Not only Casualty Officers, but many other postgraduates will also find it helpful; it contains many useful lists, tables and differential diagnoses which the M.R.C.P. candidate is expected to know. 